\title{
Heavy Metal Resistance Strategies of Acidophilic Bacteria and Their Acquisition: Importance for Biomining and Bioremediation
}

\author{
Claudio A. Navarro, Diego von Bernath and Carlos A. Jerez* \\ * Laboratory of Molecular Microbiology and Biotechnology, Department of Biology, Faculty of Sciences, University of Chile, Santiago, Chile
}

\begin{abstract}
Microbial solubilizing of metals in acid environments is successfully used in industrial bioleaching of ores or biomining to extract metals such as copper, gold, uranium and others. This is done mainly by acidophilic and other microorganisms that mobilize metals and generate acid mine drainage or AMD, causing serious environmental problems. However, bioremediation or removal of the toxic metals from contaminated soils can be achieved by using the specific properties of the acidophilic microorganisms interacting with these elements. These bacteria resist high levels of metals by using a few "canonical" systems such as active efflux or trapping of the metal ions by metal chaperones. Nonetheless, gene duplications, the presence of genomic islands, the existence of additional mechanisms such as passive instruments for $\mathrm{pH}$ and cation homeostasis in acidophiles and an inorganic polyphosphate-driven metal resistance mechanism have also been proposed. Horizontal gene transfer in environmental microorganisms present in natural ecosystems is considered to be an important mechanism in their adaptive evolution. This process is carried out by different mobile genetic elements, including genomic islands (GI), which increase the adaptability and versatility of the microorganism. This mini-review also describes the possible role of GIs in metal resistance of some environmental microorganisms of importance in biomining and bioremediation of metal polluted environments such as Thiomonas arsenitoxydans, a moderate acidophilic microorganism, Acidithiobacillus caldus and Acidithiobacillus ferrooxidans strains ATCC 23270 and ATCC 53993, all extreme acidophiles able to tolerate exceptionally high levels of heavy metals. Some of these bacteria contain variable numbers of GIs, most of which code for high numbers of genes related to metal resistance. In some cases there is an apparent correlation between the number of metal resistance genes and the metal tolerance of each of these microorganisms. It is expected that a detailed knowledge of the mechanisms that these environmental microorganisms use to adapt to their harsh niche will help to improve biomining and metal bioremediation in industrial processes.
\end{abstract}

Key words: Heavy metal resistance, genomic islands, environmental bacteria, biomining, metal bioremediation, mobile genetic elements

\section{INTRODUCTION}

Many environmental microorganisms have adapted to the presence of toxic heavy metals. In general, when cellular metals concentrations exceed acceptable levels, mechanisms of resistance are activated in order to survive this adverse environment (Rensing and Grass, 2003; Franke and Rensing, 2007; Magnani and Solioz, 2007; Kim et al., 2010; Dupont et al., 2011). In Gram-negative bacteria, one of the pathways described for metal resistance is the active efflux of metal from the cytoplasm to the periplasmic space, carried out by ATPases located in the internal membrane of the bacteria (Rensing and Grass, 2003). Some microorganisms may pump metal from the cytoplasm directly to the extracellular space by systems of the RND (resistance nodulation cell division) family of carriers, the Cus system of E. coli being the best known of this kind of detoxification organization (Outten et al., 2001). The capacity of some species to bind the metal in the periplasmic space by means of metal chaperones has also been reported for copper (Puig et al., 2002; Kim et al., 2010).

An important strategy used by all microorganisms to survive a toxic flux of metals is the formation of biofilms. Metal sequestration takes place in biofilms since extracellular polymers, cell membranes and cell walls of the microbial community provide many cationic and anionic sites for the interaction with metal ions and their biosorption (Harrison et al., 2007).
In the environment of biomining microorganisms, copper and other nominal metal concentrations are one or two orders of magnitude greater than those tolerated by neutrophiles (Remonsellez et al., 2006; Orell et al., 2010; Orell et al., 2013). However, since the growth conditions of these two types of bacteria are completely different the comparison cannot be directly made. As already mentioned, these apparent metal resistance differences might be due in some cases to a different availability of the metals and differences in uptake of cations between neutrophiles and acidophiles.

Acidophilic microorganisms have several active mechanisms to withstand their extremely acidic environment (Dopson et al., 2003; Franke and Rensing, 2007; Krulwich et al., 2011). In addition, some passive mechanisms of $\mathrm{pH}$ homeostasis have been proposed to support the active mechanisms. Some strategic changes in proton permeability of the membrane and cell surface changes have been thought to delay proton entry into or loss from the cytoplasm (Krulwich et al., 2011). Examples of these possible passive systems have been reported for $A$. ferrooxidans, the most studied biomining bacterium. This microorganism has an unusual pI profile which may not only address functional needs but could also provide a passive contribution to the active mechanisms for $\mathrm{pH}$ homeostasis (Jerez, 2013). Surface proteins in $A$. ferrooxidans have high $\mathrm{pI}$ values relative to neutrophilic bacteria, so their positive charges could act as a transient proton repellent at the cell surface (Chi et al., 2007). 
Adjustments of membrane lipids and porins have also been proposed in A. ferrooxidans to minimize inward proton leakage during acid stress (Krulwich et al., 2011 and references therein). Porins are organized in trimeric structures that form water-filled channels that allow diffusion of small molecules through the outer membrane. Each monomer constitutes a discrete pore. Within each pore of OmpC from E. coli a long polypeptide loop (L3) runs along one side of the barrel wall and narrows the pore to create an "eyelet" region (Nikaido, 1994). The net electric charge of these loops 3 is important for the permeability of the molecules passing through the pore. Comparing a cross-section of a pore from E. coli and one possibly existing in OMP40, the major porin from $A$. ferrooxidans (Guiliani and Jerez, 2000), the net charge of loop 3 in $A$. ferrooxidans would be +2 at its usual growth $\mathrm{pH}$ of 2.5, while the equivalent loop in the neutrophilic E. coli would have a net charge of -4 at its growth $\mathrm{pH}$ of 7.0. Therefore the A. ferrooxidans loop could act as a proton barrier to control the free entry of protons from the outside and thus avoid excessive acidification of their periplasmic space (Guiliani and Jerez, 2000; Jerez, 2013). A great reduction in the expression levels of OMP40 has been observed by quantitative proteomics in A. ferrooxidans ATCC 233270 cells grown in the presence of copper, strongly suggesting a change in the permeability of the outer membrane to decrease copper ion entrance to the cell and thus to prevent toxicity of the heavy metal (Almárceguie et al., 2013a). Thus the properties of OMP40 would not only be a passive strategy as already mentioned but would function together with other envelope proteins such as a new RND-type efflux pump and a putative periplasmic disulfide isomerase, both being apparently regulated copper-resistance determinants in this extremophile (Almárcegui et al., 2013b). A similar result has been observed in Pseudomonas aeruginosa, in which a reduced expression of eight different porins was seen when cells were exposed to copper (Teitzel et al., 2006).

Horizontal gene transfer (HGT) is considered to be an important mechanism for the evolution of microbial genomes, since together with gene loss and other genomic alterations, gene acquisition has an important role in the adaptive evolution of microorganisms (Dobrindt et al., 2004). Great advances have been made over the past ten years in understanding the mechanisms of genomic variability and evolution of bacterial pathogens, especially due to the interest in knowing the mechanisms of antibiotic resistance in pathogenic bacteria. Knowledge of HGT in environmental microorganisms present in natural ecosystems has also begun to accumulate (Aminov, 2011). Recent comparison of gene-transfer networks amongst hundreds of sequenced genomes has suggested that on average $20 \%$ of the genes have been recently acquired (Popa et al., 2011; Polz et al., 2012). Highly sophisticated natural genetic engineering tools in the form of a variety of mobile genetic elements (MGEs) are considered to be central to HGT-driven bacterial evolution and adaptation (Dobrindt et al., 2004; Aminov, 2011). Although new classifications of MGEs are continuously appearing, in general they include conjugative transposons, integrons, plasmids, bacteriophages, genomic islands (GIs), transposons and insertion sequence elements (Dobrindt et al., 2004; Aminov, 2011).

GIs are large chromosomal regions that are part of a flexible gene pool. These DNA regions would have been previously transferred by other MGEs and they carry one or more genes that can increase the adaptability and versatility of the microorganism. They have been defined in general as clusters of genes having one or a set of the following properties (Dobrindt et al., 2004; van Houdt et al., 2009): a tyrosine-based site-specific recombinase gene and an adjacent tRNA gene at one extremity; flanking insertion sequence elements; a base composition and/or phylogeny differing from the bulk of the genome, indicating acquisition through HGT; higher content of hypothetical genes than neighboring regions; clustering of genes characteristic of MGEs such as recombinase genes and IS elements; conservation of the GI between different (unrelated) hosts; a high concentration of genes specialized for resistance, catabolism and unusual metabolism.

In the present mini-review we will focus on recent findings related to metal resistance mechanisms and to the role of GIs that confer high metal resistance in some acidophilic environmental microorganisms of importance in biomining and bioremediation of metal-polluted environments. Important related reviews og non-acidophilic environmental microorganisms are also available (Von Rozycki and Nies, 2009; Boyd et al., 2009; Hemme et al., 2010; Mijnendoncx et al., 2011).

Thiomonas

Acid mine drainage (AMD), usually derived from biomining operations to recover metals, contains highly toxic elements and a very low pH (Mohapatra et al., 2011; Jerez, 2011). Nevertheless, several microorganisms are associated with this extreme environment. Among these bacteria and archaea, Thiomonas are found, especially in AMD containing levels up to $6 \mathrm{mM}$ of inorganic forms of arsenite (As(III)) (Table 1) and arsenate $(\mathrm{As}(\mathrm{V}))$ (Arsène-Ploetze et al., 2010). Thiomonas arsenitoxydans (formerly Thiomonas sp. 3As) belongs to the Beta-proteobacteria and is a facultative chemolithoautotroph, moderate acidophile ( $\mathrm{pH}$ 5), able to grow optimally in mixotrophic media containing reduced inorganic sulfur compounds and organic supplements (Bryan et al., 2009, Duquesne et al., 2008). Thiomonas spp. have been described as being capable to oxidize arsenite. These microorganisms may be quite useful to minimize the toxicity of As(III) in arsenicpolluted environments (Duquesne et al., 2008).

The genome of $T$. arsenitoxydans (Slyemi et al., 2011) contains a circular chromosome of $3.7 \mathrm{Mpb}$ and a plasmid (pTHI) of $46.8 \mathrm{Kpb}$ (Arsène-Ploetze et al., 2010). The circular chromosome contains 19 GIs (ThGEI-A-ThGEI-S) that were acquired by HGT. It has been proposed that these GIs confer a series of adaptive advantages to the bacterium to colonize its niche efficiently, such as the acquisition of genes coding for genetic products implicated in heavy metal resistance. On the other hand, plasmid pTHI contains 68 coding regions. among which 14 would potentially code for proteins involved in conjugation. It has been suggested that $T$. arsenitoxydans may be able to express a complete type IV secretory system that would be required directly for DNA and protein translocation to the outside of the bacterial cell (Arsène-Ploetze et al., 2010).

Regarding heavy metal resistance, $T$. arsenitoxydans has two GIs coding for operons related to copper resistance: ThGEI-J, containing a partial cus operon, and ThGEI-O, that includes genes coding for partial cop and cus systems (ArsènePloetze et al., 2010). These authors compared the genome of T. arsenitoxydans to the genome of several other Thiomonas strains. They found that their flexible gene pool evolved to allow their growth and survival in their toxic environment. The results of Arsène-Ploetze et al, 2010 suggested that the 


\section{TABLE 1}

Metal tolerances $(\mathrm{mM})$ of some acidophilic and neutrophilic microorganisms

\begin{tabular}{|c|c|c|c|c|c|c|}
\hline Microoraganism & $\mathrm{Cu}^{2+}$ & $\mathrm{As}^{3+}$ & $\mathrm{Zn}^{2+}$ & $\mathrm{Cd}^{2+}$ & $\mathrm{Ni}^{2+}$ & Reference \\
\hline Acidithiobacillus ferrooxidans & 800 & 84 & 1071 & 500 & 1000 & Dopson et al., 2003 and references therein \\
\hline Acidithiobacillus caldus DSM8584 * & 24 & N.D. & N.D. & N.D. & N.D. & Watkin et al., 2008 \\
\hline Cupriavidus metallidurans $\mathrm{CH} 34$ * & 3 & 4 & 12 & 4 & 13 & Monsieurs et al., 2011 \\
\hline Thiomonas cuprina DSM 5495 ** & 7.9 & 1.3 & 150 & 0.09 & 170 & Schippers 2007 \\
\hline Thiomonas arsenitoxydans & N.D. & 6 & N.D. & N.D. & N.D. & Arsène-Ploetze et al., 2010 \\
\hline Metallosphaera sedula DSM 5348 ** & 16 & 1.3 & 150 & 0.9 & N.D. & Hubber et al.,1989 \\
\hline Escherichia coli $\mathrm{K} 38$ * & $1^{\mathrm{b}}$ & $4^{\mathrm{a}}$ & $1^{\mathrm{b}}$ & $0.5^{\mathrm{b}}$ & $1^{\mathrm{b}}$ & aCarlin et al., b Nies 1999 \\
\hline Sulfolobus solftaricus & 1 & N.D. & 10 & 10 & 0.1 & Miller et al., 1992 \\
\hline
\end{tabular}

* Minimum Inhibitory Concentration (MIC) values

** Metal concentration where metabokic activity still takes place

N.D. Not determinated

natural environment influences the genomic evolution of these bacteria. As in the case of A. ferrooxidans to be reviewed in the next section, the acquisition by strains of the same species of different GIs highlights the genomic variability within a given taxonomic group.

\section{Acidithiobacillus ferrooxidans}

A. ferrooxidans is a Gram-negative, acidophilic chemolithoautotroph that can use ferrous iron, reduced species of sulfur or metal sulfides as energy sources (Vera et al., 2013; Rawlings, 2005; Valenzuela et al., 2006; Jerez, 2008; Jerez, 2011). As shown in Table 1, some strains of A. ferrooxidans can resist exceptionally high copper (up to $800 \mathrm{mM} \mathrm{CuSO}_{4}$ ) and other metal concentrations (Dopson et al., 2003; Orell et al., 2010). This property is important for the use of this microorganism in biomining processes, where copper levels usually range between 15 and $100 \mathrm{mM} \mathrm{CuSO}_{4}$ (Watling, 2006; Watling et al., 2010).

A. ferrooxidans ATCC 23270 can survive high copper concentrations by having in its genome at least ten genes that are possibly related to copper homeostasis. These include three genes coding for putative ATPases related to the transport of copper $\left(\operatorname{cop} A 1_{A f^{\prime}} \operatorname{cop} A 2_{A f^{\prime}}\right.$ and $\left.\operatorname{cop} B_{A f}\right)$, three genes related to a system of the RND family, involved in the extraction of copper from the cell by using the proton motive force $\left(\right.$ cus $\left.A_{A f^{\prime}} c u s B_{A f^{\prime}} c u s C_{A f}\right)$, and two genes coding for periplasmic chaperones for this metal ( $c u s F_{A f}$ and $\operatorname{cop} C_{A f}$ ) (Navarro et al., 2009). The expression of most of these open reading frames (ORFs) was studied by real time RT-PCR (qRT-PCR) using $A$. ferrooxidans cells that were adapted to grow in the presence of high concentrations of $\mathrm{CuSO}_{4}$. These $A$. ferrooxidans copperresistance determinants were found to be upregulated when this bacterium was exposed to $\mathrm{CuSO}_{4}$ in the range of 5 to 25 $\mathrm{mM}$ and conferred to E. coli a greater resistance to copper compared to wild-type cells, supporting their functionality (Navarro et al., 2009).

The genomic sequence of $A$. ferrooxidans ATCC 53993 contains all the copper-resistance genes present in $A$. ferrooxidans ATCC 23270 that have been experimentally confirmed as being expressed in the presence of copper, except that strain ATCC 23270 contains a second Cus-like operon interrupted by a transposase gene which is absent in the genome of strain ATCC 53993 (Luo et al., 2008; Navarro et al., 2009; Orell et al., 2010; Orellana and Jerez, 2011). These ORFs have $100 \%$ identity between their corresponding DNA sequences. However, A. ferrooxidans ATCC 53993 contains several additional putative metal-resistance ORFs that confer it higher metal resistance (Orellana and Jerez, 2011). These putative genes are clustered in a $160 \mathrm{~kb}$ GI that is absent in the genome of A. ferrooxidans strain ATCC 23270 (Orell et al., 2010; Cardenas et al., 2010). On the other hand, strain ATCC 23270 has a $300 \mathrm{~kb}$ region that does not contain metal resistancerelated genes and is absent in the genome of strain ATCC 53993 (Cardenas et al., 2010; Bustamante et al., 2012).

Genomic strain variations have also been found in the acidophilic Leptospirillum group II by deep metagenomic genome sequence analysis (Simmons et al., 2008). It is possible that HGTs shared by $A$. ferrooxidans strains and other microorganisms are key elements to supplement metal resistance and possibly other properties, thus conferring adaptive advantages to all these microorganisms.

The GI found exclusively in A. ferrooxidans ATCC 53993 contains genes encoding heavy metal resistance determinants, such as those involved in mercury detoxification (mer $A$ ), incorporation of the metal to the cytoplasm where it is reduced and volatilized $(\operatorname{mer} C)$ and the transcriptional regulator $(m e r R)$, as well as a copper translocating P-type ATPase. This GI is inserted after ORF Lferr0127, which has been annotated as an enzyme related to t-RNA metabolism (MiaB type). Six ORFs possibly related to $\mathrm{Cu}$-resistance are present in this GI: a P-type ATPase annotated as a possible $\mathrm{Cu}$-resistance determinant or $\operatorname{cop} A 3_{A f}$ (Orellana and Jerez, 2011). All Cop-like proteins found so far in $A$. ferrooxidans, including $\operatorname{CopA}_{\mathrm{Af}}$ contain the metal binding motifs that are highly conserved in Cop proteins from other microorganisms (Orell et al., 2010).

Other ORFs found in the GI of A. ferrooxidans ATCC 53993 corresponded to members of a putative Cus system (cus $A 3_{A f^{\prime}}$ ${ }{ }_{\text {usB }} 3_{A f}$ and $\operatorname{cusC} 3_{A f}$ ). Two additional possible CusF-like chaperones previously described in A. ferrooxidans ATCC 23270 (Navarro et al., 2009) were found in this GI (Orellana and Jerez, 2011).

The copper-binding site of E. coli CusF contains one His and two Met in addition to an unusual Trp that presumably interacts with copper through a cation- $\pi$ interaction (Xue et al., 
2008). All the putative CusF-like proteins from A. ferrooxidans strains ATCC 23270 and ATCC 53993 contain a Met instead of a His in their putative binding sites (Orell et al., 2010). In addition, their amino acid sequences have possible signal peptides, suggesting that all are exported, most likely to the periplasmic space.

A. ferrooxidans ATCC 53993 has a much higher resistance to $\mathrm{CuSO}_{4}(>100 \mathrm{mM})$ than that of strain ATCC $23270 \quad(<25$ $\mathrm{mM}$ ) (Orellana and Jerez, 2011). As occurs in Cupriavidus metallidurans, it was expected that the additional multiplicity of possible copper resistance determinants in the GI of $A$. ferrooxidans ATCC 53993 would confer it a higher tolerance to the metal compared to strain ATCC 23270. Although both strains have similar growth in the absence of copper, cell numbers of ATCC 23270 were reduced 7-fold when grown in $100 \mathrm{mM} \mathrm{CuSO}{ }_{4}$, whereas those of ATCC 53993 were diminished by only 2-fold (Orellana and Jerez, 2011; Jerez, 2013). This additional capacity of strain ATCC 53993 to tolerate copper should give it an adaptive advantage when growing in a microbial consortium such as the one usually found in their habitat. If these two $A$. ferrooxidans strains were present in a bioleaching operation such as a heap or more likely in an industrial biooxidation reactor, as copper concentration increases with the dissolution of the mineral, at the end of the operation strain ATCC 53993 should predominate over ATCC 23270. A preliminary test of this idea was carried out by growing a mixture of approximately equivalent numbers of each strain in the presence of copper. The relative proportions of each kind of bacterium were estimated by means of qPCR by using strain-specific primers. These results clearly indicated that A. ferrooxidans ATCC 53993 was able to outgrow strain ATCC 23270 in the presence of $50 \mathrm{mM} \mathrm{CuSO}_{4}$ (Orellana and Jerez, 2011; Jerez, 2013).

Furthermore, an upregulation of the transcriptional expression of most of the additional $\mathrm{Cu}$-resistance genes present in the GI of A. ferrooxidans ATCC 53993 was observed when cells were grown in the presence of increasing $\mathrm{CuSO}_{4}$ concentrations. These genes were also functional when expressed in E. coli, strongly supporting the functionality of the copper-resistance determinants present in the GI of $A$. ferrooxidans ATCC 53993 (Orellana and Jerez, 2011). These findings constitute the first experimental evidence for high copper resistance due to the expression of genes present in a GI of an acidophilic chemolithoautotrophic bacterium. It will be of great interest to establish in future studies whether all the remaining putative and hypothetical genes present in the GI of A. ferrooxidans ATCC 53993 have a role in conferring the bacterium extra resistance, not only to copper but also to several other metals found in bioleaching habitats.

Interestingly, when A. ferrooxidans strains ATCC 53993 vs ATCC 23270 subjected to $0 / 40 \mathrm{mM}$ copper were analyzed by differential quantitative proteomics, only 3 proteins changed in the former vs 16 proteins in the latter (unpublished results). This greatly diminished response to the metal is in good agreement with the much higher copper resistance of $A$. ferrooxidans ATCC 53993 already described.

Clearly then, the reason for resistance to copper of two strains of the same acidophilic microorganism could be determined by slight differences in their genomes generated by genetic exchanges. These inter-population interactions may not only lead to changes in the capacities of the bacteria to adapt to their environment, but may also help to select the more fit microorganisms for improvement of industrial biomining operations.

A preliminary study of the response to copper of an A. ferridurans strain D2 isolated from a copper bioleaching operation in Atacama Desert, Chile has been reported. By using whole-genome DNA microarrays, genes related to copper stress response were found to be upregulated. In addition, some genes related to other metabolic pathways were repressed, probably because of the energy cost of the stress response (Salazar et al., 2013).

Acidithiobacillus caldus

Apparently, acidophilic microorganisms use similar metal homeostatic strategies to those of neutrophils. In a recent study of zinc tolerance in Acidithiobacillus caldus ATCC 51756 and other microorganisms using bioinformatics analysis (Mangold et al., 2013), the authors predicted the presence of several zinc transporters for putative metal -import or -export which are found in other microorganisms. However, they found experimentally that many of the putative zinc homeostasis genes were constitutively expressed and with one exception, they were not upregulated in the presence of excess zinc (Mangold et al., 2013). They proposed that possible solution effects might influence the toxicity of the tested metal. Zinc speciation modeling of the growth media demonstrated that a large fraction of the free metal ion was complexed, potentially affecting its toxicity in spite of the high nominal zinc concentrations used (Mangold et al., 2013). Considering this report, a similar case could occur for $\mathrm{Zn}$ and other metals such as copper in other acidophilic microorganisms. However, the aforementioned much greater copper resistance of A. ferrooxidans strain ATCC 53993 compared to strain 23270 subjected to the same copper concentrations could not be attributed to this possible metal complex formation, since the solution conditions would be equivalent for both types of microorganisms.

Our bioinformatic analysis of the putative zinc transporters reported for A. caldus ATCC 51756 (Mangold et al., 2013), showed that all of them were also present in the genome of A. caldus SM-1. In addition, the latter strain contains seven genes in its megaplasmid pLAtcm (You et al., 2011) that may also be involved in $\mathrm{Zn}$ resistance. Atc_m073 could be involved in zinc entrance to the cell, since it codifies for an NRAMP family protein that may be involved in cation transport. The other six genes may be involved in zinc efflux. Atc_m084-m082 would form an RND type efflux system similar to ZntA. Genes Atc_m074 and Atc_075 could code for two CDF type proteins similar to CzcD, and finally, Atc_m086 is a possible P-type ATPase.

Regarding copper tolerance of $A$. caldus, a copper MIC of $24 \mathrm{mM}$ has been reported for strain DSM8584 (Watkin et al., 2008) (Table 1). Recently, the response of a Chinese strain of A. caldus to copper stress was analyzed (Xia et al., 2010). The authors found a negative effect on the activity of some of the enzymes involved in sulfur metabolism, such as sulfite oxidase and APS reductase. Nevertheless, no direct evidence was reported to support the idea of overexpression of a $\mathrm{Cu}$-specific inducible ATPase pump that the authors speculated that would be present under their study conditions.

Some of the genes related to zinc resistance reported in A. caldus ATCC 51756 (Mangold et al., 2013) and those 
already mentioned for the megaplasmid of strain SM-1 that may be possible zinc transporters could also be involved in copper transport (see Table 2). Specifically, the RND type efflux systems and P-type ATPases, since these genes have been previously reported as related to copper resistance in $A$. ferrooxidans ATCC 23270 (Navarro et al., 2009; Orellana and Jerez, 2011).

Both strains of $A$. caldus contain a variety of genes coding for putative copper resistance-related proteins, since they showed a high degree of identity (between 50 and 90\%) with those known for A. ferrooxidans (Navarro et al., 2009; Orellana and Jerez, 2011). These two strains of A. caldus share several of these genes in their chromosomal DNA, such as the components of an RND-type efflux pump (CusABC), two P-type ATPases (CopB), two cytoplasmic metalochaperones (CopZ) and a copper oxidase (CueO) (Table 2). However, the megaplasmid pLAtcm present in strain SM-1 (You et al., 2011) contains a great variety of genes related to heavy metal resistance. Specifically, six of these genes may be involved in copper resistance. Except for $\mathrm{CueO}$, all the copper resistance determinants present in the chromosome of $A$. caldus strain SM-1 are duplicated in the megaplasmid (Table 2). Interestingly, a gene coding for a putative periplasmic copper chaperone (CusF), which has been described in E. coli (Loftin et al., 2005) and in A. ferrooxidans ATCC strains 23270 and 53993 (Orell et al., 2010; Orellana and Jerez, 2011), is also present in the pLAtcm megaplasmid but absent in the chromosomal DNA from both ATCC 51756 and SM-1 A. caldus strains (Table 2).

Are canonical metal resistance determinants able to confer high metal tolerance to microorganisms?

C. metallidurans $\mathrm{CH} 34$ contains many genes for copper resistance and has a MIC value of $3 \mathrm{mM}$ for copper (Monsieurs et al., 2011). On the other hand, P. syringae pv. tomato containing only one copRSABCD operon for copper resistance has also a MIC value of $3 \mathrm{mM}$ (Nakajima, 2002). In addition, some microorganisms such as A. ferrooxidans ATCC 23270 or Metallosphaera sedula that do not contain metal resistance genes in their GIs, are still highly resistant to heavy metals (Table 1 ). This suggests that there is not always a direct correlation between the number of genes related to metal resistance and greater metal resistance in all microorganisms.

Previous reports have indicated that $A$. ferrooxidans ATCC 23270 resists copper in part by the use of a combination of an ample collection of recognized copper resistance genes (Orell et al., 2010; Wu et al., 2010). A. ferrooxidans ATCC 53993 has a much higher resistance to copper than strain ATCC 23270 most likely due to the presence of the exclusive GI in the former. Nevertheless, at present the participation of other unknown genes in the high Cu-resistance of strain ATCC 53993 cannot be discounted. As already pointed out in Table 1, A. ferrooxidans strains are able to grow in extremely high $\mathrm{CuSO}_{4}$ concentrations (Das et al., 1998; Wu et al., 2010). Other non-acidophilic microorganisms able to grow in the presence of several toxic metals, such as $C$. metallidurans, tolerate $\mathrm{CuSO}_{4}$ in a much lower range (1.5 to $12.5 \mathrm{mM}$ ) (Chen et al., 2008). Nevertheless, this property of $C$. metallidurans has also been attributed to the occurrence of a great variety of metal resistance determinants, many of them present in GIs (van Houdt et al., 2009). Although as already mentioned it is not possible to compare MIC values of microorganisms growing in entirely different media, the presence of metal resistance genes in genomic islands may be a general strategy used by environmental microorganisms to tolerate high levels of toxic metals.

Is a PolyP-based metal resistance mechanism present in all highly metal resistant microorganisms?

The existence in acidophiles of genes with similarity to most of the Cu-resistance determinants contained in neutrophilic microorganisms does not completely explain the much higher metal resistance of the former microorganisms. One of the possible additional mechanisms proposed for metal resistance is the sequestration of metal cations with long polymers of inorganic polyphosphate (polyP) (Rao et al., 2009; Keasling, 1997). PolyP is a linear polymer of hundreds of orthophosphate residues linked by phosphoanhydride bonds. The main enzyme involved in the biosynthesis of polyP is the polyphosphate kinase (PPK) that catalyzes the reversible conversion of the terminal phosphate of ATP into polyP. On the other hand, an exopolyphosphatase (PPX) is known to

TABLE 2

Bioinformatic search of putative copper resistance determinants in Acidithiobacillus caldus strains compared to those in $A$. ferrooxidans

\begin{tabular}{cccc} 
& \multicolumn{2}{c}{ A. caldus SM-1 } & A. caldus ATCC 51756 \\
\hline Model gene & Chromosome & Megaplasmid & Chromosome \\
\hline CusA $_{A f}$ & Atc_1883 & Atc_m082 & ACA_0623 \\
CusB $_{A f}$ & Atc_1884 & Atc_m083 & ACA_0624 \\
CusC $_{A f}$ & Atc_1885 & Atc_m084 & ACA_0625 \\
CusF $_{A f}$ & - & Atc_m079 & - \\
CopB $_{A f}$ & Atc_1890; Atc_2814 & Atc_m086 & ACA_0628; ACA_1351 \\
BsCopZ & Atc_1888; Atc_2815 & Atc_m088 & ACA_0626; ACA_1352 \\
EcCueO & Atc_1364 & - & ACA_1571 \\
\hline
\end{tabular}

Copper-resistance determinants were searched in the genomes from A. caldus strains SM-1 and ATCC 51756 by making a BLAST search using the sequences of copperresistance related proteins previously reported in $A$. ferrooxidans ATCC 23270 (Navarro et al., 2009) and 53993 (Orellana and Jerez, 2011 ): CusCFBA $A_{A f}, C_{\text {CopA }}$, CopB $_{A f}$ and $\mathrm{CopC}_{A f}$ 'or in E. coli (EcCueO) and B. subtilis (BsCopZ). 
hydrolyze polyP, liberating inorganic phosphate (Pi) (Rao et al., 2009). PolyP is synthesized by PPK in A. ferrooxidans or other bacteria (or by a yet unknown equivalent archaeal enzyme) using ATP (Jerez, 2011; Orell et al., 2010; Orell et al., 2012). Several biomining microorganisms have been shown to accumulate electron-dense granules composed of polyP as seen in the bacteria $A$. ferrooxidans, $A$. caldus, $A$. thiooxidans and in the archaea Sulfolobus metallicus and M. sedula (Orell et al., 2010; Orell et al., 2012). In this regard, polyP granules have also been observed in electron micrographs of thin sections of T. arsenitoxydans (Arséne-Ploetze et al., 2010).

Thus a polyP-dependent system for $\mathrm{Cu}$-resistance has been proposed for A. ferrooxidans (Alvarez and Jerez, 2004) and S. metallicus (Remonsellez et al., 2006), reviewed in Orell et al., (2012). This resistance mechanism is based on the observed in vitro activation of PPX by the presence of intracellular copper (Alvarez and Jerez, 2004). The phosphate released from polyP would form a metal-phosphate complex that would be eliminated from the cell through inorganic phosphate transporters (Pho84 type, since the acidophiles discussed here do not have the standard Pit-like bacterial phosphate transporters).

In excess of ADP generated by the use of cellular ATP, the reverse reaction of PPK synthesizes additional ATP from polyP. In this way, the reserve polyP would also be supplying energy to the metal detoxifying systems. A similar mechanism may also exist in Sulfolobales (Orell et al., 2010; Orell et al., 2012; Orell et al., 2013). Although the proposed mechanism for metal resistance needs to be proven, it may be eventually functional in all polyP-accumulating biomining microorganisms (Orell et al., 2010) (see Fig. 2).

While a connection between $\mathrm{pH}$ homeostasis and metal homeostasis is not yet clear, it is a known fact that polyP has a high buffering capacity, being able to neutralize protons and metals that could be incorporated into the cytoplasm (Rao et al., 2009). In this connection, it has been proposed that cytoplasmic buffering in T. arsenitoxydans can be mediated not only by amino acid decarboxylation but also by polyP granules (Arsène-Ploetze et al., 2010).
Recently, Mangold et al., 2013 also reported by means of a bioinformatics analysis that $A$. caldus ATCC 51756 contains all the genes putatively involved in the polyP-based resistance mechanism.

Regarding the system needed to incorporate inorganic phosphate into the cells, A. ferrooxidans contains in its genome a putative Pho regulon including the genes $p h o B$, phoR, pstS, pstC, pst $A, p s t B, p h o U, p p x$ and ppk (Vera et al., 2003). Some differences were seen in the organization of the genes from $A$. ferrooxidans compared to the Pho operons from other bacteria. This was especially evident in the organization of the genes involved in polyP metabolism ( $p p k$ and $p p x)$. E. coli has both $p p k$ and $p p x$ genes in the same operon (Rao et al., 2009), while A. ferrooxidans does not (Vera et al., 2003). Therefore, if the E. coli genes are co-regulated at the transcriptional level it is difficult to envisage an accumulation of polyP granules, since the two enzymes have opposite activities (synthesis versus degradation of polyP). In fact, E. coli only transiently increases polyP synthesis under adverse conditions, and no polyP granules have been reported in wild type strains of this bacterium. One could speculate that microorganisms having the $p p k$ and $p p x$ genes organized in separate operons could regulate synthesis and degradation of polyP separately, allowing them to accumulate these polymers in response to stressing conditions. As already mentioned, this is in agreement with the great capacity of $A$. ferrooxidans to accumulate polyP granules. A. caldus, which also accumulates polyP granules, (Orell et al., 2012) also contains a putative Pho regulon (Mangold et al., 2013). Figure 1 shows the genomic contexts of Pho regulons for A. ferrooxidans and A. caldus. Both kinds of acidophiles have $p p x$ forming part of their respective putative operons and $p p k$ is separated from the pstS systems. Considering the similarity between these genes and their contexts, it may be suggested that these bacteria have similar ways to respond to copper and other metals, as suggested in the working models illustrated in Fig. 2. When external $\mathrm{Cu}$ concentration increases, all of the $\mathrm{Cu}$ resistance determinants from $A$. ferrooxidans or A. caldus would be expressed at higher levels to eliminate $\mathrm{Cu}$ from the periplasm or cytoplasm of the

\section{Acidithiobacillus ferrooxidans}

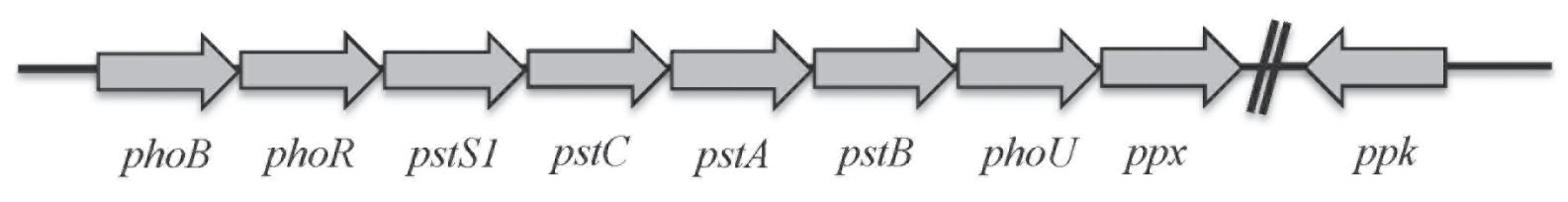

\section{Acidithiobacillus caldus}

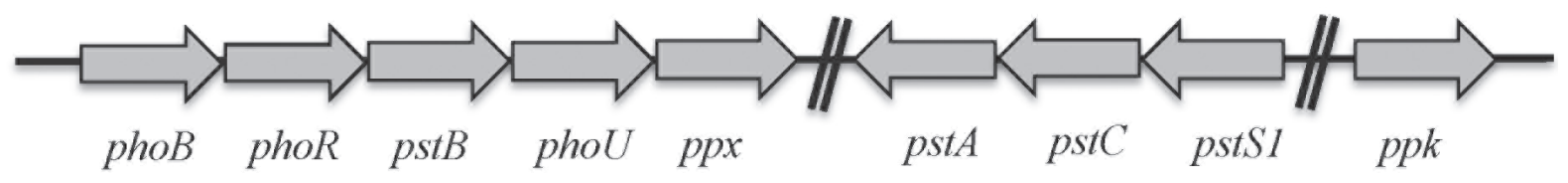

Figure 1. Putative PHO regulon in A.ferrooxidans and A. caldus. Both A. ferrooxidans strains ATCC 23270 and 53993 contain the same genes and in the same order in their respective genomes. Both $A$. caldus strains ATCC 51756 and SM-1 contain the same genomic context for the putative PHO regulon genes, which is different than that of $A$. ferrooxidans strains. 
A

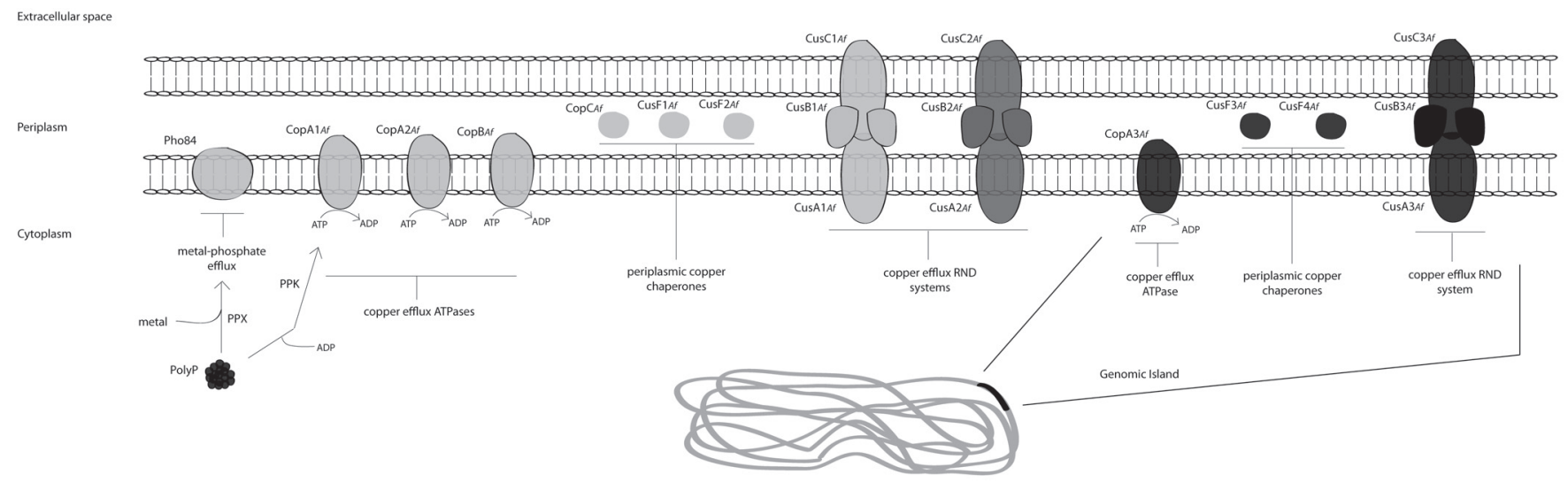

B

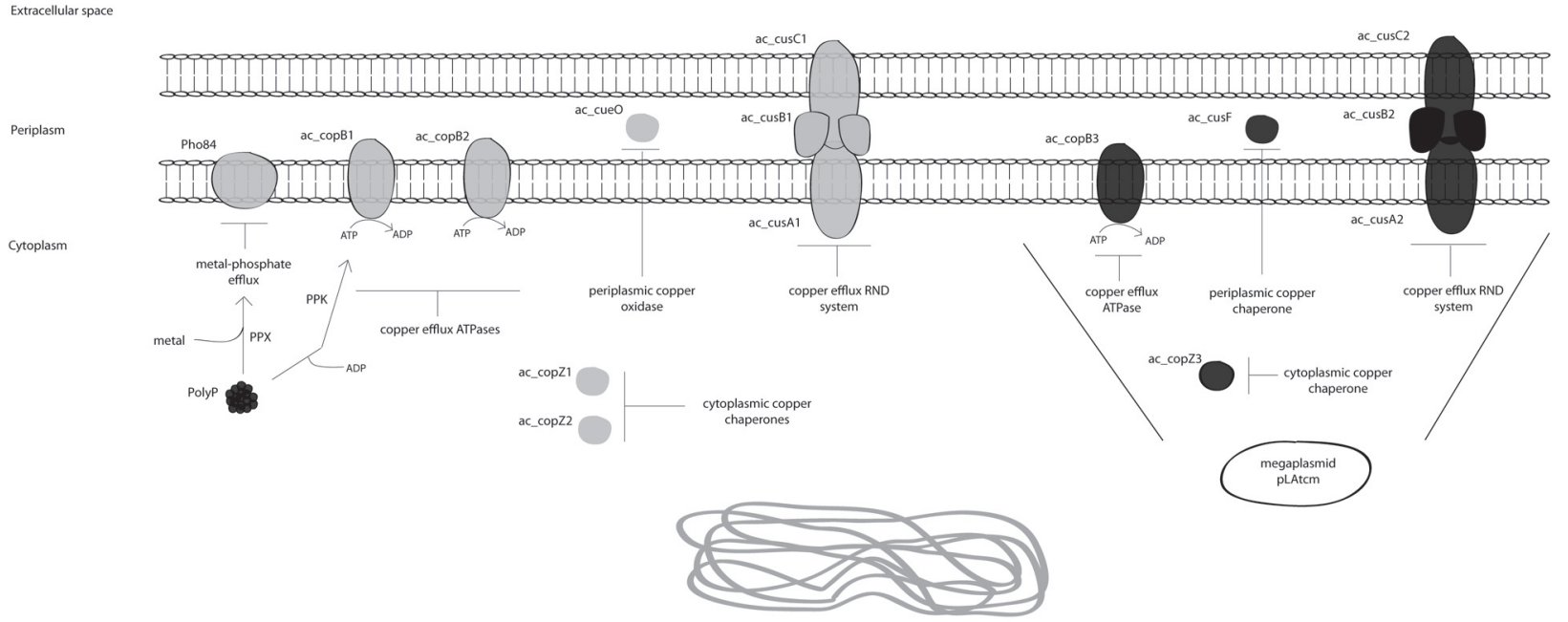

Figure 2. Working model comparing the copper resistance determinants from $A$. ferrooxidans and $A$. caldus. A. Scheme of $A$. ferrooxidans ATCC 53993 showing copper efflux ATPases, copper chaperones, copper efflux RND systems and the phosphate transporter Pho84 previously reported for $A$. ferrooxidans ATCC 23270 (Navarro et al., 2009; Orellana and Jerez, 2011; Almárcegui et al., 2013a). In addition, the extra proteins involved in copper resistance coded for in its exclusive genomic island are also included. Both $A$. ferrooxidans strains contain the same copper resistance genes in their genomes, except for those present in the genomic island of ATCC 53993. B. Proposed possible copper resistance determinants for $A$. caldus strain SM1 based on bioinformatics analysis and similarity comparison (Table 2) with the genes previously described for copper resistance in $A$. ferrooxidans.

cells. This requires high levels of ATP to activate the metal efflux ATPases and could be provided from polyP by the reverse reaction catalyzed by PPK in the presence of excess ADP in the cell.

\section{CONCLUDING REMARKS}

Current knowledge indicates that key elements involved in metal resistance in environmental microorganisms appear to be a wide repertoire of known metal-resistance determinants and their duplication, the presence of novel metal-chaperones and abundant reserve of inorganic polyphosphate (polyP) used in a polyP-based copper resistance system. The study of novel metal resistance determinants in environmental microorganisms will also help with the functional annotation of these genes in the increasingly available genomic sequences from environmental extremophilic bacteria and archaea.
Horizontal gene transfer by means of mobile genetic elements such as genomic islands plays an important role in increasing the adaptability and versatility of environmental microorganisms living in environments with high metal concentrations. The characterization of metal resistance determinants will not only contribute to our understanding of the mechanisms that acidophilic bioleaching and other microorganisms use to adapt to their extreme environments but to eventually improve biomining or metal bioremediation processes as well. This could be achieved by using the fittest bacteria in these industrial processes.

\section{ACKNOWLEDGEMENTS}

The authors thank FONDECYT 1110214 and ICM P-05-001-F projects. 


\section{REFERENCES}

ALMARCEGUI RJ, NAVARRO C, PARADELA A, ALBAR JP, VON BERNATH D, JEREZ CA (2013a) New copper resistance determinants in the extremophile Acisithiobacillus ferrooxidans: a quantitave proteomic analysis. J Proteome Res DOI: 10.1021/ pr4009833.

ALMARCEGUI RJ, NAVARRO C, PARADELA A, VON BERNATH D, JEREZ CA (2013b) Novel cell envelope proteins related to copper resistance in Acidithiobacillus ferrooxidans. Adv Mat Res 825:206-209.

ÁLVAREZ S, JEREZ CA (2004) Copper ions stimulate polyphosphate degradation and phosphate efflux in Acidithiobacillus ferrooxidans. Appl Environ Microbiol 70:5177-5182.

AMINOV RI (2011) Horizontal gene exchange in environmental microbiota. Front Microbiol 2:158. doi:10.3389/fmicb.2011.00158.

ARSĖNE-PLOETZE F, KOECHLER S, MARCHAL M, COPPÉ JY, CHANDLER M, BONNEFOY V, BOCHIER-ARMANET C, BARAKAT M, BARBE V, BATTAGLIA-BRUNET F, BRUNEEL O, BRYAN CG, CLEISS-ARNOLD J, CRUVEILLER S, ERHARDT M, HEINRICH-SALMERON A, HOMMAIS F, JOULIAN C, KRIN E, LIEUTAUD A, LIÈVREMONT D, MICHEL C, MULLER D, ORTEL P, PRPUX C, SIGUIER P, ROCHE D, ROUY Z, SALVIGNOL G, SLYEMI D, TALLA E, WEISS S, WEISSENBACH J, MEDIGUE C, BERTIN PN (2010) Structure, function, and evolution of the Thiomonas sp. Genome. PLOS Genet 6: e1000859.

BOYD EF, ALMAGRO-MORENO S, PARENT MA (2009) Genomic islands are dynamic, ancient integrative elements in bacterial evolution. TRENDS Microbiol 17: 47-53.

BRYAN CG, MARCHAL M, BATTAGLIA-BRUNET F, KUGLER V, LEMAITRE-GUILLIER C, LIÈVREMONT D, BERTIN PN, ARSÈNEPLOETZE F (2009) Carbon and arsenic metabolism in Thiomonas strains: differences revealed diverse adaptation processes. BMC Microbiol 9: 127.

BUSTAMANTE P, COVARRUBIAS PC, LEVICÁN G, KATZ A, TAPIA P, HOLMES D, QUATRINI R, ORELLANA O (2012) ICEAfe1, an actively excising genetic element from the biomining bacterium Acidithiobacillus ferrooxidans. J Mol Microbiol Biotechnol 22:399-407.

CÁRDENAS JP, VALDÉS J, QUATRINI R, DUARTE F, HOLMES DS (2010) Lessons from genomes of extremely acidophilic bacteria and archaea with special emphasis on bioleaching microorganisms. Appl Microbiol Biotechnol 88:605-620.

CARLIN A, SHI W, DEY S, ROSEN BP (1995) The ars operon of Escherichia coli confers arsenical and antimonial resistance. J Bacteriol 177:981-986.

CHEN WM, WU CH, JAMES EK, CHANG JS (2008) Metal biosorption capability of Cupriavidus taiwanensis and its effects on heavy metal removal by nodulation Mimosa pudica. J Hazardous Mat 151:364-371

CHI A, VALENZUELA L, BEARD S, MACKEY AJ, SHABANOWITZ J, HUNT DF, JEREZ CA (2007) Periplasmic proteins of the extremophile Acidithiobacillus ferrooxidans: a high throughput proteomic analysis. Mol Cell Proteomics 6:2239-2251.

DAS A, MODAK JM, NATARAJAN KA (1998) Surface chemical studies of Thiobacillus ferrooxidans with reference to copper tolerance. Antonie van Leeuwenhoek 73:215-222.

DOBRINDT U, HOCHHUT B, HENTSCHEL U, HACKER J (2004) Genomic islands in pathogenic and environmental microorganisms. Nature Rev Microbiol 2:414-424.

DOPSON M, BAKER-AUSTIN C, KOPPINEEDI PR, BOND PL (2003) Growth in sulfidic mineral environments: metal resistance mechanisms in acidophilic micro-organisms. Microbiology 149:1959-1970.

DUPONT CL, GRASS G, RENSING G (2011) Copper toxicity and the origin of bacterial resistance-new insights and applications. Metallomics DOI: $10.1039 / \mathrm{c} 1 \mathrm{mt} 00107 \mathrm{~h}$

DUQUESNE K, LIETAUD A, RATOUCHNIAK J, MULLER D, LETT MC, BONNEFOY V (2008) Arsenite oxidation by a chemoautotrophic moderately acidophilic Thiomonas $s p$ : from the strain isolation to the gene study. Environ Microbiol 10: 228-237.

FRANKE S, RENSING C (2007) Acidophiles. Mechanisms to tolerate metal and acid toxicity. In: Gerday C, Glansdorff N (eds.) Physiology and biochemistry of extremophiles. ASM Press, Washington DC. pp 271-278.

GUILIANI N, JEREZ, C.A. (2000) Molecular cloning, sequencing, and expression of omp-40, the gene coding for the major outer membrane protein from the acidophilic bacterium Thiobacillus ferrooxidans. Appl Environ Microbiol 66:2318-2324.

HARRISON JJ, CERI H, TURNER RJ (2007) Multimetal resistance and tolerance in microbial biofilms. Nature Rev Microbiol 5:928-938.

HEMME CL, DENG Y, GENTRY TJ, FIELDS MW, WU L, BARUA S, BARRY $\mathrm{K}$, TRINGE SG, WATSON DB, HE Z, HAZEN TC, TIEDJE JM, RUBIN
EM, ZHOU J (2010) Metagenomic insight into evolution of a heavy metalcontaminated groundwater microbial community. ISME J 4: 660-672.

HUBER G, SPINNLER C, GAMBACORTA A, STETTER KO (1989) Metallosphaera sedula gen. and sp. nov represents a new genus of aerobic, metal mobilizing, thermoacidophilic archaebacteria. Syst Appl Microbiol 12: 38-47.

JEREZ CA (2008) The use of genomics, proteomics and other OMIC technologies for the global understanding of biomining microorganisms. Hydrometallurgy 94:162-169.

JEREZ CA (2011) Bioleaching and biomining for the industrial recovery of metals. In: M Moo-Young (ed) Comprehensive Biotechnology. Second Edition. volume 3. pp: 717-729.

JEREZ, C.A. (2013) The use of extremophilic microorganisms in industrial recovery of metals. In: Songh, O. (ed) Extremophiles: Sustainable Resources and Biotechnological Implications. John Wiley \& Sons, Inc. pp. 319-334.

KEASLING JD (1997) Regulation of intracellular toxic metals and other cations by hydrolysis of polyphosphate. Ann NY Acad Sci 829:242-249.

KIM E-H, RENSING C, McEVOY MM (2010) Chaperone-mediated copper handling in the periplasm. Nat Prod Rep 27:711-719.

KRULWICH TA, SACHS G, PADAN E (2011) Molecular aspects of bacterial pH sensing and homeostasis. Nature Rev. Microbiol. 9:330-343.

LOFTIN IR, FRANKE S, ROBERTS SA, WEICHSEL A, HÉROUX A, MONTFORT WR, RENSING C., McEVOY MM (2005) A novel copperbinding fold for the periplasmic copper resistance protein CusF. Biochemistry 44: 10533-10540.

LUO Y, LIU Y, ZHANG C, LUO H, GUAN H, LIAO H, QIU G, LIU X (2008) Insights into two high homogenous genes involved in copper homeostasis in Acidithiobacillus ferrooxidans. Curr Microbiol 57:274-280.

MAGNANI D, SOLIOZ M (2007) How bacteria handle copper. In: Nies DH, Silver S (eds.) Bacterial transition metal homeostasis. Springer, Heidelberg. pp 259-285.

MANGOLD S, POTRYKUS J, BJÖRN E, LÖVGREN L, DOPSON, M (2013) Extreme zinc tolerance in acidophilic microorganisms from the bacterial and archaeal domains. Extremophiles 17:75-85.

MIJNENDONCKX K, PROVOOST A, MONSIEURS P, LEYS N, MERGEAY M, MAHILLON J, VAN HOUDT R (2011) Insertion sequence elements in Cupriavidus metallidurans $\mathrm{CH} 34$ : distribution and role in adaptation. Plasmid 65: 193-203.

MILLER KW, RISANICO SS, RISATTI JB (1992) Differential tolerance of Sulfolobus strains to transition-metals. FEMS Microbiol Lett 93:69-73.

MOHAPATRA BR, GOULD WD, DINARDO O, KOREN DW (2011) Tracking the prokaryotic diversity in acid mine drainage-contaminated environments: a review of molecular methods. Min Eng 24: 709-718.

MONSIEURS P, MOORS H, VAN HOUDT R, JANSSEN PJ, JANSSEN A, CONINX I, MERGEAY M, LEYS N (2011) Heavy metal resistance in Cupriavidus metallidurans CH34 is governed by and intrincate transcriptional network. Biometals DOI 10.1007/s10534-011-9473-y.

NAKAJIMA M, GOTO M, HIBI T (2002) Similarity between copper resistance genes from Pseudomonas syringae pv. Actinidae and P. syringae pv. tomato. J Gen Plant Pathol 68:68-74.

NAVARRO CA, ORELLANA LH, MAURIACA C, JEREZ CA (2009) Transcriptional and functional studies of Acidithiobacillus ferrooxidans genes related to survival in the presence of copper. Appl Environ Microbiol 75:6102-6109.

NIES DH (1999) Microbial heavy-metal resistance. Appl Microbiol Biotechnol 51: 730-750.

NIKAIDO H (1994) Porins and specific diffusion channels in bacterial outer membranes. J Biol Chem 269:3905-3908.

ORELL A, NAVARRO CA, ARANCIBIA R, MOBAREC JC, JEREZ CA (2010) Life in blue: copper resistance mechanisms of bacteria and Archaea used in industrial biomining of minerals. Biotechnol Adv 28:839-848.

ORELL, A., NAVARRO, C.A., RIVERO, M., AGUILAR, J.S., AND JEREZ, C.A. (2012) Inorganic polyphosphates in extremophiles and their possible functions. Extremophiles 16:573-583. DOI. 1007/s00792-0120457-9.

ORELL, A., REMONSELLEZ, F., ARANCIBIA R., AND JEREZ, C.A. (2013) Molecular characterization of copper and cadmium resistance determinants in the biomining thermoacidophilic archaeon Sulfolobus metallicus. Archaea. Volume 2013, Article ID 289236, DOI: $10.1155 / 2013 / 289236,16$ pages.

ORELLANA LH, JEREZ CA (2011) A genomic island provides Acidithiobacillus ferrooxidans ATCC 53993 additional copper resistance: a possible competitive advantage. Appl Microbiol Biotechnol 92:761-767. 
OUTTEN FW, HUFFMAN DL, HALE JA, O`HALLORAN TV (2001) The independent cue and cus system confer copper tolerance during aerobic and anaerobic growth in Escherichia coli. J Biol Chem 276:30670-30677.

POPA O, HAZKANI-COVO E, LANDAN G, MARTIN W, DAGAN T (2011) Directed networks reveal genomic barriers and DNA repair bypasses to lateral gene transfer among prokaryotes. Genome Res 21: 599-609.

POLZ MF, ALM EJ, HANAGE WP (2012) Horizontal gene transfer and the evolution of bacterial and archaeal population structure. Trends Genet 29:170-175.

PUIG S, REES EM, THIELE DJ (2002) The ABCDs of periplasmic copper trafficking. Structure 10:1292-1295.

RAO NN, GÓMEZ-GARCÍA MR, KORNBERG A (2009) Inorganic polyphosphate: Essential for growth and survival. Annu Rev. Biochem 78:605-647.

RAWLINGS DE (2005) Characteristics and adaptability of iron- and sulfuroxidizing microorganisms used for the recovery of metals from minerals and their concentrates. Microb Cell Fact 4:13.

REMONSELLEZ F, ORELL A, JEREZ CA (2006) Copper tolerante of the thermoacidophilic archaeon Sulfolobus metallicus: possible role of polyphosphate metabolism. Microbiol 152:59-66.

RENSING C, GRASS G (2003) Escherichia coli mechanism of copper homeostasis in a changing environment. FEMS Microbiol Rev 27:197213.

SALAZAR C, ACOSTA M, GALLEGUILLOS P, SHMARYAHU A, QUATRINI R, HOLMES DS, DEMERGASSO C (2013) Analysis of gene expression in response to copper stress in Acidithiobacillus ferrooxidans strain D2, isolated from a copper bioleaching operation. Adv Mat Res 825:157-161.

SCHIPPERS A (2007) Microorganisms involved in bioleaching and nucleicacid based molecular methods for their identification. In: Donati ER, Sand W (eds.) Microbial processing of metal sulfides. Springer. pp 3-33.

SIMMONS SL, DIBARTOLO G, DENEF VI, GOLTSMAN DSA, THELEN MP, BANFIELD JF (2008) Population genomic analysis of strain variation in Leptospirillum Group II bacteria involved in acid mine drainage formation. PLoS Biol 7:e177.

SLYEMI D, MOINIER D, BROCHIER-ARMANET C, BONNEFOY V, JOHNSON DB (2011) Characterization of a phylogenetically ambiguous, arsenic-oxidizing Thiomonas sp., Thiomonas arsenitoxydans strain 3As(T) sp. nov. Arch Microbiol 193:439-449.

TEITZEL, G.; GEDDIE, A.; DE LONG, S.; KIRISITS, M.; WHITELEY, M.; PARSEK, M (2006) Survival and growth in the presence of elevated copper: Transcriptional profiling of copper-stressed Pseudomonas aeruginosa. Journal of Bacteriology 188:7242-7256.

VALENZUELA L, CHI A, BEARD S, ORELL A, GUILIANI N, SHABANOWITZ J, HUNT DF, JEREZ CA (2006) Genomics, metagenomics and proteomics in biomining microorganisms. Biotech Adv 24:197-211.

VAN HOUDT R, MONCHY S, LEYS N, MERGERAY M (2009) New mobile elements in Cupriavidus metallidurans $\mathrm{CH} 34$, their possible roles and occurrence in other bacteria. Antoine van Leeuwenhoek 96: 205-226.

VERA M, GUILIANI N, JEREZ CA (2003) Proteomic and genomic analysis of the phosphate starvation response of Acidithiobacillus ferrooxidans. Hydrometallurgy 71:125-132.

VERA M, SCHIPPERS A, SAND W (2013) Progress in bioleaching: fundamentals and mechanism of bacterial metal sulfide oxidationpartA. Appl Microbiol Biotechnol 97:7529-7541.

VON ROZYCKI T, NIES DH (2009) Cupriavidus metallidurans: evolution of a metal-resistance bacterium. Antoine van Leeuwenhoek 96: 115-139.

WATKIN ELJ, KEELING SE, PERROT FA, SHIERS DW, PALMER ML, WATLING HR (2008) Metals tolerance in moderately thermophilic isolates from a spent copper sulfide heap, closely related to Acidithiobacillus caldus, Acidimicrobium ferrooxidans and Sulfobacillus thermosulfidooxidans. J Ind Microbiol Biotechnnol 36:461-465.

WATLING HR (2006) The bioleaching of sulphide minerals with emphasis on copper sulphides-A review. Hydrometallurgy 84:81-108.

WATLING HR, WATKIN ELJ, RALPH DE (2010) The resilience and versatility of acidophiles that contribute to the bio-assisted extraction of metals from mineral sulphides. Env Technol 31:915-933.

WU X, HU Q, HOU D, MIAO B, LIU X (2010) Differential gene expression in response to copper in Acidithiobacillus ferrooxidans strains possessing dissimilar copper resistance. J Gen Appl Microbiol 56:491-498.

XIA L, YIN C, CAI L, QIU G, QUIN W, PENG B, LIU J. (2010) Metabolic changes of Acidithiobacillus caldus under $\mathrm{Cu}^{2+}$ stress. J Basic Microbiol 50:591-598.

XUE Y, DAVIS AV, BALAKRISHNAN G, STASSER JP, STAEHLIN BM, FOCIA P, SPIRO TG, PENNER-HAHN JE, O'HALLORAN TV (2008) Cu (I) recognition via cation- $\pi$ and methionine interactions in CusF. Nature Chem Biol 4:107-109.

YOU XY, GUO X, ZHENG HJ, ZHANG MJ, LIU LJ, ZHU YQ, ZHU B, WANG SY, ZHAO GP, POETSCH A, JIANG CY, LIU SJ (2011) Unraveling the Acidithiobacillus caldus complete genome and its central metabolisms for carbon assimilation. J Genet Genomics 38:243-252. 
